\title{
P100 Latency
}

National Cancer Institute

\section{Source}

National Cancer Institute. P100 Latency. NCI Thesaurus. Code C117888.

An assessment of the latency of the P100 or P1 wave of the visual evoked potential assessment waveform. 